\title{
Financial Leverage and Its Impact on Profit Margin in Pakistan's Textile Industry
}

\author{
Sohaib Uz Zaman $^{1 *} \quad$ Dr.A.R.Zaki ${ }^{2} \quad$ Dr. Danish Ahmed Siddiqui ${ }^{3}$ \\ 1.Karachi University Business School, University of Karachi. Main University Road Karachi - 75270. Sindh, \\ Pakistan \\ 2.Dept. of Business Administration, Sir Syed University of Engineering and Technology, ST-16 University Rd, \\ Block 5 Gulshan-e-Iqbal, Karachi, Karachi City, Sindh \\ 3.Karachi University Business School, University of Karachi. Main University Road Karachi - 75270. Sindh, \\ Pakistan
}

\begin{abstract}
The core purpose concerned in this study remains to explore the impact of the financial leverage on the stitched textile industry, and mainly on the profit margin. The textile industry in Pakistan is said to be the largest manufacturing industry and so is the stitching industry increasing with the great importance of readymade dresses especially among females. The objective set in this study remains to study the relationship between the Financial Leverage (FL) and the Profit Margin (PM). This further includes the proving of the idea that the stitched industry becomes more profitable as soon as the financial leverage has been adopted by the companies. The data from 10 Stitched-Textile companies has been gathered as a sample in this study, from the period of 2012 to 2015 for data analysis. The tools used for data analysis comprised of descriptive analysis, correlation analysis,and regression analysis. The results from this analysis conclude that in the stitching industry there is no significance recognition but positive impact on the FL by the PM. Therefore, it is being recommended that the best possible use of the FL should be made by the stitched industry in order to achieve the target of becoming the most profitable industry of Pakistan Textile Industry. Furthermore, it could be noted that the optimum increase in the production of the textile industry would help in minimizing the level of poverty in Pakistan and also building a healthy population.

Keywords: Financial Leverage; Profit Margin, Stitched-Textile Industry, profitability.
\end{abstract}

DOI: $10.7176 /$ EJBM/11-12-13

Publication date: April $30^{\text {th }} 2019$

\section{Introduction}

There are numerous ways in which the strategies are deployed by the businesses in order to improve the profitability of the organizations. These strategies include processes like integrating the latest technology, streamlining and outsourcing and integrating new technologies. However, financial leverage is said to be offering an alternative method of increasing the profits, in which a complete portion of the businesses has been financed through loans(Gatsi, Gadzo, \& Akoto, 2013).

The use of the FL is not always profitable for all types of businesses, hereby, in each business, its importance and usage varies. This also refers to the idea that the businesses utilizing the FL are required to be coping with the degree of uncertainty concerning their future sales, however, this is risk lesser than the risk of failure of the businesses due to the offering of the latest and experimental products and services. On the other hand, the businesses which offer products and services that acquire a demonstrable record would be helping them securing the financial leverage at better rates (Nissim \& Penman, 2003).

Same aspects could be seen in the textile industry, where those companies which use the FL successfully, shown by them through their success in handling the risk essential to carrying their debts. The FL becomes the most important factor for increasing the profitability of the companies at times when decisions for additional financing is considered. This piece of work will be based on exploring the use and impact of FL on the profit margin of the Stitched industries in Pakistan (Awan, 2016).

\section{Objectives of the Study}

The primary objective of this study remains to determine the relationship between Financial Leverage and Profit Margin in the Stitched Textile Industry of Pakistan.

\section{Literature Review}

In this part of the paper, the use of extensive theoretical and empirical bodies would be helping in successfully inspecting the impact of the financial leverage on profitability. This literature review would further signify the relationship between Financial Leverage and Profit Margin.

Considered the theory suggested by Myer and Majluf whenever there is an imbalance in the investment and the cash flow faced by the companies, they are left with only two choices (Gersbach, Haller, \& Müller, 2015). One is to opt for financial leverage, which would help in paying off the outstanding debt, else they have to issue their 
safest securities in order to raise the cash. Whilst more clearly the companies are having three financing resources, which include debt, equity and internal funds(Baron, 1976).

This has been countered by the Pecking Theory, which states that the internal directors are with a better understanding of the financial upbringing of the companies, and hereby they could take better decisions in regard to financing the business by making use of funds from various sources(Serrasqueiro \& Caetano, 2015). Furthermore, the preference set by this theory remains that the companies should be looking forward to financing from the internal assets and prioritize it over external funding(Ali, 2011).

On contrary, Myer and Majluf put forward the idea that if a company depends totally on the benefit held by it and so the value financing could not be included for assisting in financial issues, at that point the information asymmetry can be developed (Jang, 2009). Subsequently offering fresh stocks accessible to be bought impacts the offer to get cost to deteriorate, companies should refrain from offering such low-value securities and slope towards issuing commitment while relying upon external financing (Serrasqueiro \& Caetano, 2015).

The profit margin is said to be the measure of profitability, or in other words, the total amount of profit that has been gained through the overall sale. The profit helps in understanding the situation of the businesses, a highprofit margin usually indicates that the business is a high margin business. However, low-profit-margin indicates that the business is a low margin business (Awan, 2016). This further influence the investment and future of the businesses, and so the operational decisions of the businesses vary according to their situation. These decisions further include the decision of continuing with the same strategy or looking forward to changing it, in order to gain better profits in the future (Nissim \& Penman, 2001).

This has been the same case in the textile industry, where at first the stitch clothes were high on demand, while with the change of time and need, not the readymade garments are more preferred. Even though this industry emerged as the smallest industry in Pakistan, but it's high attraction for the businessmen caused it to grow fast and smooth manner (Mandelker \& Rhee, 1984).

For the growth of every industry or business, there is always a need of finance that could be attained through any of the means of financing, which are internal funds, equity, and debt. Here the internal funds and equity are subject to the finances already carried by the business while the debt is the finance that could be acquired as an external help (Baron, 1976).

The loans could be beneficial to the textile industries by all means that the ready-made garments are found to be paying back in a short period of time. However, the unstitch industry have more uncertainties as compared to the stitched industry which would cause the industries to look up for high risk, if working leverage has been considered for financing (Awan, 2016).

The financial leverage refers to the amount of debt that has been held by the industries in order to pursue their desired production and for paying the cost of the supplies or buying the asserts through them. This has been preferably used to decrease the use of the excessive use of equity, which may cause a high risk to the industry (Nissim \& Penman, 2003). The textile industry, which has also been taken as a seasonal market as well, could take a decision on the leverages by first ensuring that the payback from the sales would be profitable for them in future so that the leverage is taken for this purpose (Ali, 2011).

This refers to the idea that the financial leverage taken by the industries, has a great impact on its profit margin, and hence it is greater than the usual profit. This is important due to the fact that the industry has to pay back the leverage before the due time, else they would deliberate get caught into the issue of high debts and surplus interest to be paid for the delayed payback, or even bankruptcy(Nissim \& Penman, 2003).

\section{Research Methodology}

This study has been conducted by making use of secondary data taken from my thesis, which is based on textile industry data. The data used in this article is from 10 well known Stitched Textile Industry of Pakistan, for the time period from 2012 to 2015 . The variables that have been studied in this article are Profit margin and Financial Leverage.

\section{Model Estimation and Specification}

There is only one dependent and one independent variable is chosen for this study, that are, Profit Margin (PM) and Financial Leverage (FL) respectively. The analysis has been drawn to analyze the impact of FL on the PM by making use of regression analysis(Asgher, Yasmeen, \& Iqbal, 2014). This could be seen from the Table 1.The regression model that would be used for this analysis is provided beneath:

General Regression Model:

$\hat{\mathrm{Y}}=\alpha+\beta_{1} \mathrm{X}_{1}+\overline{\mathrm{e}}_{\mathrm{i}, \mathrm{t}}$

Regression Model for this study:

$\mathrm{PM}=\alpha+\beta_{1} \mathrm{FL}+\overline{\mathrm{e}}_{\mathrm{i}, \mathrm{t}}$

Where,

$\mathrm{PM}=$ Profit Margin 
And

$\mathrm{FL}=$ Financial Leverage

\begin{tabular}{|c|c|c|}
\hline \multicolumn{3}{|c|}{ Table 1: Dependent and Independent Variables chosen for the Model } \\
\hline Category & Variable & Expected Relationship \\
\hline Dependent variable & Profit Margin (PM) & Positive/Negative \\
\hline Independent variable & Financial Leverage (FL) & Positive/Negative \\
\hline
\end{tabular}

\section{Hypothesis}

The methodology suggests that the regression analysis would be used for the analysis of the model. In order to conduct this analysis following hypothesis would be used:

- $\mathrm{H}_{0}$ : Null Hypothesis: There is a significant relationship between the dependent and independent variable

- $\mathrm{H}_{1}$ : Alternative hypothesis: There is not a significant relationship between the dependent and independent variable

\section{Important Variables}

The two important variables used in this study FL and PM. Below is a detailed understanding of these two variables.

\section{Financial Leverage (FL)}

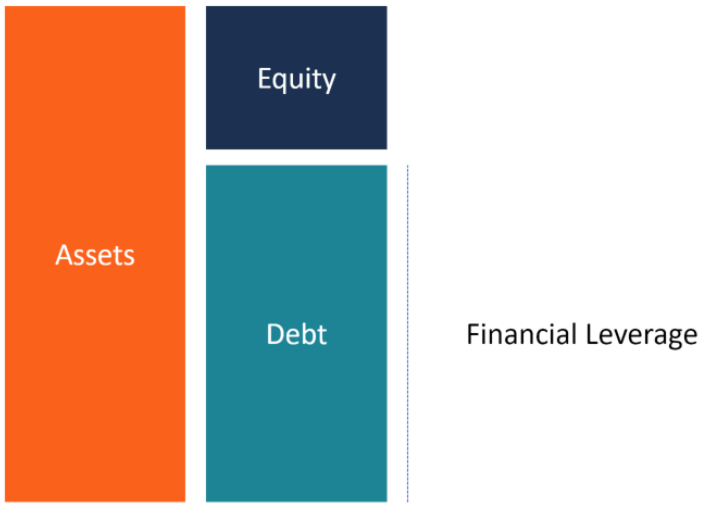

Figure 1 Financial Leverage (FL)

Financial leverage is the utilization of money that has been borrowed from an external source, mostly from banks. The need for attaining FL arises in order to purchase assets so that higher income could be generated, which would definitely exceed the cost paid for borrowing(Baron, 1976).

By and large, the supplier of the FL will put a limit on how much leverage could be taken. If in case the loan has been taken is backed by assets, the supplier utilizes the benefits from these assets as an insurance until the point that the borrower reimburses the credit. While industries also look forward to cash flow loans, the general financial soundness of the industry is utilized to back the loan rather than the assets (Mandelker \& Rhee, 1984).

The formula used for calculating the FL in this study is as follows:

\section{FL $=\underline{\text { Percentage Change in EPS }}$ \\ Percentage Change in EBIT}

Where,

EPS $=$ Earnings per Share

$\mathrm{EBIT}=$ Earnings Before Income and Tax

\section{Profit Margin (PM)}

The profit margin, additionally known as the gross profit ratio or return on sales ratio, is one of the profitability ratios which estimates the measure of net incomes held with every dollar of offers created by looking at the net sales and net income of the industries. At the end of the day, the overall profit margin demonstrates what level of sales is left over after all costs are paid by the concerned industry (Ali, 2011).

Investors and creditors utilize profit margin to analyze the viability of the concerned industry could change the sales into the net income. the high profits are most preferred by the investors as they have to distribute dividends, however, the concern of the creditors is constrained to the point that the profits generated by the company are enough to pay back the leverage on time (Mandelker \& Rhee, 1984). The formula used in this study in order to calculate the profit margin is as follows: 


\section{Profit Margin $=\underline{\text { Net Income }}$ \\ Net Sales}

Considering the relationship between PM and FL, it could be stated that the FLtook on long-term basis bear more chances of high PM, while these results vary business to business (Asgher, Yasmeen, \& Iqbal, 2014).

\section{Empirical Results Analysis Descriptive Statistics}

\begin{tabular}{|l|c|c|}
\hline \multicolumn{3}{|c|}{ Table 2: Descriptive Statistics } \\
\hline Stitched PM & Mean & Std. Deviation \\
\hline Stitched FL & .31 & 2.42 \\
\hline
\end{tabular}

The above table indicates the descriptive statistics of PM and FL for the chosen companies from the stitched industry. It is clear that both of these variables are having their uniquearea, which is because of the varying formulae used for their calculation. The mean for the PM is 0.3 , and the standard deviation of 2.42 shows that that the values of the ten companies chosen for the research are close to its mean and there is less variation.

Concerning the mean of the FL, it is 1.27 , for this means as well the standard deviation is not very high that is 3.16. This means that the FL taken by the ten companies are not varying to a great degree from each other. This also proves that the results generated through the analysis of these 10 companies would be meaningful.

\section{Correlation Analysis}

The correlation analysis has been used not just to analyze the relationship between the independent and dependent variables but also the strength of their relationship. PM is an essential measure for the growth and productively of the stitched industry. Considering the FL to back the production of the company, ensures that the PM of the company would increase and surplus the revenue.

In table 3, it could be seen that thePM with (0.02) is significant with the FL. This refers to the idea that for the stitched industry, would be gaining greater PM in future if they opt for FL for financing the production. In other words, the high the FL the higher would be the PM in the stitched industry of Pakistan.

\begin{tabular}{|l|l|c|c|}
\hline \multicolumn{3}{|c|}{ Table 3: Correlations } & Stitched FL \\
\hline \multirow{2}{*}{ Pearson Correlation } & Stitched PM & Stitched PM & \\
\cline { 2 - 4 } & Stitched FL & 1 & 1 \\
\hline
\end{tabular}

\section{Regression Analysis}

Model Summary

The regression analysis in this article has been used toanalyze and understand the relationship between FL and PM.The results for regression analyze generated from SPSS software are provided in Table 4 below. The test has been applied to take the value of the level of significance at $5 \%$.

\begin{tabular}{|l|c|c|c|c|c|c|c|}
\hline \multicolumn{1}{|c|}{ Variables } & Coefficient & $\boldsymbol{P}$-value & $\boldsymbol{R}$ & R-Square & F-Test & Sig F & $\begin{array}{c}\text { Durbin- } \\
\text { Watson }\end{array}$ \\
\hline Intercept & 0.21 & 0.00 & 0.102 & 0.01 & 0.397 & 0.53 & 1.9 \\
\hline Stitched FL & 0.078 & 0.03 & 0.107 & \\
\hline
\end{tabular}

In the above linear regression equation, the relationship between FL and PM has been analyzed. As indicated in the methodology, the model that would be analyzed is as follows:

$\mathrm{PM}=\alpha+\beta_{1} \mathrm{FL}+\overline{\mathrm{e}}_{\mathrm{i}, \mathrm{t}}$

This clearly that the dependent variable is PM (Profit Margin), and the independent variable is FL (Financial Leverage). Through the results of analysis above this could now be written as:

$\mathrm{PM}=0.21+0.78 \mathrm{FL}$

In this model, the coefficient of FL is $0.78(0.03)$. the positive coefficient indicates that there is a positive relationship between the dependent and independent variable. Since the p-value of FL is less than the level of significance i.e. 0.05 , hereby, we reject the alternative hypothesis. Further, it could be stated that there is a significant relationship between PM and FL.

Considering the R Square value, it could be seen that it is very low, which is due to the single variable is used for testing the PM, however, it has many others affecting its value. There are high chances that if the independent variables are increased then the value of $\mathrm{R}$ square would also increase.

Concerning the value of Durbin-Watson, which is 1.9 , and is $<2$, indicates that there is a positive correlation between the variables. This shows that the fast-growing stitched textile industry of Pakistan should be opting for the use of higher FL. 


\section{Conclusion}

The article was aimed at analyzing the relationship between profitability and leverage in the stitched textile industry. The variables chosen for this analysis were PM and FL dependent variable and independent variable, respectively. The regression analysis was used for indicating this relationship, using stitched textile industry data based on 10 companies from the year 2012 till 2015 .

The results obtained from this analysis determined that there is a positive relationship between the two variables. This refers to the idea that the profitability of the stitched industry has higher chances of growing if the companies opt for leverage. This could be asserted from the focus of the literature review which details that the growth leverage could help the industries on increasing their profit to such an extent that they would surplus the revenue normally generated by them.

Hereby, the FL with appropriate strategies is highly recommended to the stitched textile industries. While the same case could not be applied to the unstitched industry due to the varying aspects acquired by it. The impact of FL could also be tested against the Return on Assets (ROA), Return on Equity (ROE) and other profitability ratios, which would provide more definite and factual results and recommendation for the stitched in regard to the use of the FL to increase their profitability.

\section{Reference}

Ali, S. (2011). Working Capital Management and the Profitability of the Manufacturing Sector: A Case Study of Pakistan's Textile Industry. Lahore Journal of Economics, 16(2), 141-178.

Awan, A. G. (2016). Determinants of Capital Structure of Textile Industry in Pakistan. Industrial Engineering Letters, 6(1), 56-64.

Baron, D. P. (1976). Default Risk and the Modigliani-Miller Theorem: A Synthesis. The American Economic Review, 66(1), 204-212.

Gatsi, J. G., Gadzo, S. G., \& Akoto, R. K. (2013). Financial and Operating Leverage and Profitability of Insurance Firms in Ghana. International Business Management, 7(2), 57-65.

Gersbach, H., Haller, H., \& Müller, J. (2015). The Macroeconomics of Modigliani-Miller. Journal of Economic Theory, 157, 1081-1113.

Gersbach, H., Haller, H., \& Müller, J. (2015). The Macroeconomics of Modigliani-Miller. Journal of Economic Theory, 157, 1081-1113.

Jang, S. (2009). Simultaneous Impacts of International Diversification and Financial Leverage On Profitability. Journal of Hospitality \& Tourism Research, 33(3), 347-368.

Mandelker, G., \& Rhee, S. G. (1984). The Impact of the Degrees of Operating and Financial Leverage on Systematic Risk of Common Stock. Journal of Financial and Quantitative Analysis, 19(01), 45-57.

Nissim, D., \& Penman, S. H. (2001). Financial Statement Analysis of Leverage and How It Informs About Profitability and Price-to-Book Ratios. Social Science Research Network.

Nissim, D., \& Penman, S. H. (2003). Financial statement analysis of leverage and how it informs about profitability and price-to-book ratios. Review of Accounting Studies, 8(4), 531-560.

Serrasqueiro, Z., \& Caetano, A. (2015). Trade-Off Theory versus Pecking Order Theory: capital structure decisions in a peripheral region of Portugal. Journal of Business Economics and Management, 16(2), 445-466. 